\title{
El paper de la dona en la premsa tortosina en català (1900-1936)
}

\section{Woman's Role In The Catalan Tortosin Press (1900-1936)}

\section{RESUM}

L'abast d'aquest estudi comprèn des de la publicació del primer setmanari escrit en català a Tortosa al tombant del segle xx, La Veu de Tortosa, fins a l'esclat de la Guerra Civil amb el setmanari Lluita, i centra l'interès en el tractament de la dona com a tema i la intervenció d'aquesta en la premsa tortosina del primer terç del segle $\mathrm{xx}$.

Es tracta majoritàriament de premsa comarcal que reflectia el catalanisme conservador -La Veu de Tortosa (1899-1902), La Veu de la Comarca (1903-1909), Bolletí de la Lliga Espiritual de la Mare de Déu de la Cinta (1919-1921), La Veu de Tortosa (1930-31), La Veu Comarcal (1934-1935) i el diari Ara (1935-1936)-i la moral catòlica-Germanor i La Santa Cinta- enfront de la revista nacionalista Vida Tortosina i el quinzenari Acció, òrgans d'expressió d'Acció Catalana Republicana, i del setmanari socialista Lluita, el qual representava els interessos del proletariat al marge del catalanisme.

Palabras clave: dona tortosina, catalanisme, premsa tortosina.

\begin{abstract}
The reach of this study include from the publication of $L a$ Veu de Tortosa, the first weekly in Catalan published in Tortosa, around the beginning of the 20th century, La Veu de Tortosa, to the Spanish Civil War outbreak with the weekly Lluita, and focuses on two thematic axis: the women treatment as a subject and women writers in the press of Tortosa in the first third of the 20th century.

It covers, mainly, the comarcal press reflecting the conservative Catalanism $-\mathrm{La}$ Veu de Tortosa (1899-1902), La Veu de la Comarca (1903-1909), Bolletí de la Lliga Espiritual de la Mare de Déu de la Cinta (1919-1921), La Veu de Tortosa (1930-31), La Veu Comarcal (1934-1935) and the Ara daily (1935-1936) and the Catolic moral -Germanor and La Santa Cinta- front of the nacionalist review Vida Tortosina and the bi-weekly Acció, as the expression body of Acció Catalana Republicana, and the socialist weekly Lluita, which represents the interests of the proletariat leaving the Catalanism aside.
\end{abstract}

Keywords: woman of the Tortosa, Catalanism, tortosin press.

\section{SUMARI}

1.- Introducció. 1.1.- Context històric. 1.2.- Justificació. 2.- La dona com a tema en la premsa tortosina (1900-1936). 2.1.- La Veu de Tortosa, La Veu de la Comarca i el Bolletí. 2.2.- Vida Tortosina (1928-1936). 2.3.- La Veu Comarcal. 2.4.- Ara. 2.5.- Lluita. 3.- Col-laboracions femenines en la premsa tortosina. 3.1.- La Zuda (1913-1933). 3.2.- La Santa Cinta (1928-1936). 4.- Conclusions. Bibliografia 


\section{Introducció}

\subsection{Context històric}

La premsa escrita fou fonamental en el naixement i la difusió de les idees de l'estat liberal i en el desenvolupament de la societat contemporània. Per això, són diversos els autors que han donat una visió diacrònica sobre la producció periodística a Tortosa durant aquesta època, amb una majoria aclaparadora de premsa escrita en castellà ${ }^{2}$. Jordi Valls afirma que entre els segles XIX i Xx hi existiren al voltant d'un centenar de capçaleres (2013: 164), la majoria de les quals estigueren lligades a una opció política, bé de partit o bé personalista, la qual cosa demostra que Tortosa va conformar un espai sociopolític específic més enllà dels referents provincials de Tarragona i Reus. Hem d'entendre que la ciutat de Tortosa fou l'epicentre de la major part de la producció periodística del territori ${ }^{3}$ que avui anomenem Terres de l'Ebre $^{4}$ i que existiren tres opcions polítiques significatives que s'hi reflectien al tombant del segle xx (Valls, 2013: 159-188).

D'una banda, hi havia el carlisme, amb el qual s'identificava el bisbat tortosí. $E l$ Correo de Tortosa (1812-1936) en fou l'òrgan oficial. Altres veus més moderades dins l'Església catòlica foren representades per Correo Ibérico (1903-1908), contra el qual combaté l'integrista El Ebro (1903-07); El Restaurador (1908-20), i El Radical (1910-14).

D'altra banda, a cavall del darrer terç del segle xIx i principis del xx, hi hagué el gonzalisme, un sector polític caracteritzat per un regeneracionisme peculiar centrat en la figura de Teodor González, entre el pensament conservador -partidari de Cánovas del Castillo- i el localisme, i que serví de referent a la dreta d'avantguarda dels anys 20 i $30 \mathrm{amb}$ l'alcalde Joaquín Bau. El mitjà d'expressió per excel-lència del gonzalisme fou La Verdad (1880-1903), primer com a setmanari i, a partir de 1983, com a diari. Aquest rotatiu s'enfrontà sobretot amb Los Debates (1887-1911), que representava la veu dels seguidors del també conservador Alberto Bosch Fustegueres. El Tiempo (1907-15), imprès a Tortosa, fou l'últim òrgan oficial del partit Conservador a la província de Tarragona.

Finalment, cal parlar del marcel-linisme, que fou l'opció de l'esquerra predominant, sobretot al Baix Ebre i al Montsià, fins a la Guerra Civil. El principal òrgan d'expressió fou El Pueblo (1901-1937), convertit des de març de 1937 en El Poble i en portaveu d'ERC (Sánchez Cervelló, 2012: 348). A Amposta hi hagué el seu homòleg El Faro (1904-06). Altres nuclis marcel-linistes del Montsià foren: La Voz de Ulldecona (1915-17); l'Ideal (1933-34) -òrgan del PRRS- i La Voz de la Galera (1916).

En relació amb els liberals, cal dir que el Diario de Tortosa (1882-1923) fou el portaveu oficial del partit. També existí El Independiente (1893), que reaparegué

2 Veg. Sánchez \& Margalef (2003).

3 Abans de la Guerra Civil a Tortosa existien una desena d'impremtes, de les quals només en queden dues en l'actualitat: Impremta Querol i Impremta Algueró i Bages (Valls, 2013: 182).

4 Cal tenir present que fins a la divisió comarcal establerta per Pau Vila l'any 1931 -i que no fou definitiva fins al 1987, després de la recuperació de la Generalitat-, el territori es dividia en tres districtes electorals: Gandesa, Roquetes i Tortosa (Sánchez Cervelló, 2012: 345). 
com El Nuevo Independiente (1893-95), El Liberal del Ebro (1896-98) i El Nuevo Diario (1898-1900), que acabà fusionant-se amb el Diario de Tortosa. L'últim òrgan del partit Liberal fou La Ribera del Ebro (1915-18). I sense vinculacions partidistes nasqué Heraldo de Tortosa (1924-37), fundat per José Monllaó Panisello arran de la desaparició del Diario de Tortosa.

\subsection{Justificació}

Aquest article centra l'interès en el tractament de la dona com a nucli temàtic i la intervenció femenina en la premsa tortosina escrita en català durant el primer terç del segle $x x$, la qual cosa esdevé un tema inèdit fins ara pel seu abast geogràfic de referència. Ens cenyim, doncs, a tractar la premsa tortosina escrita en català, des de principis de segle i fins a l'esclat de la Guerra Civil. Així, parlem de La Veu de Tortosa (1899-1902), setmanari immers en l'àmbit cultural que nasqué al voltant del Seminari tortosí i afí a la Unió Catalanista5; La Veu de la Comarca (1903-1909), dirigit per Joan Abril, que fou un rotatiu proper a la Lliga Regionalista; i el Bolletí de la Lliga Espiritual de la Mare de Déu de la Cinta (1919-1921), de caràcter apolític i dirigit per Mn. Joan B. Manyà i Mn. Tomàs Bellpuig; tots tres foren el reflex del catalanisme conservador tortosí dels dos primers decennis del segle en l'àmbit de la premsa. Amb la proclamació de la II República, reapareix La Veu de Tortosa (1930-31), ara com a portaveu del partit d'Acció Regionalista, proper a la Lliga; el segueix La Veu Comarcal (1934-35), portaveu de la Lliga Comarcal Republicana, i el diari Ara (193536), afí al mateix partit.

En canvi, la revista cultural Vida Tortosina (1927-1936/7) -portaveu del partit durant onze mesos- i el quinzenari Acció (1933-34) -fundat per Joan Cid Mulet-, van representar el moderat catalanisme nacionalista d'esquerres, d'Acció Catalana Republicana al Baix Ebre.

Amb l'esclat de la revolució, el setmanari marxista-leninista Lluita, convertit en diari bilingüe a partir del núm. 14, esdevingué l'òrgan oficial d'UGT-PSUC, la força hegemònica al Baix Ebre a partir d'aleshores. Es va desmarcar, doncs, del catalanisme, malgrat que també fou escrit en català i va complir la tasca d'introduir la llengua catalana entre la classe obrera tortosina.

A banda dels rotatius esmentats, hi hagué tres revistes bilingües, dues de caràcter catòlic i conservador, Germanor (1918-36), butlletí del Col-legi St. Pere de la Salle, i La Santa Cinta (1928-1936); i el setmanari La Zuda (1913-33), butlletí de l'Ateneu de Tortosa, que tingué un abast cultural i cronològic molt més ampli.

Per tant, el corpus d'estudi d'aquest article el constitueixen': La Veu de Tortosa (162 núm. setmanals), La Veu de la Comarca (247 núm. setmanals/quinzenals), el

5 Tot i l'afinitat a la Unió Catalanista, el seu director Francesc Mestre i Noè es relega de la vida política d'ençà de la creació de la Lliga Regionalista (1901).

6 Cal dir que, entre 2011 i 2014, vam revisar tots els números que hi havia a l'Arxiu Històric Comarcal de les Terres de l'Ebre -avui anomenat Arxiu Històric del Baix Ebre- sobre les dotze publicacions, que han constituït el corpus d'estudi per a la tesi de doctorat La premsa tortosina en català del primer terç del segle Xx, llegida a la Universitat Jaume I de Castelló al gener de 2016. 
Bolletí de la Lliga Espiritual de la Mare de Déu de la Cinta (15 núm. bimensuals); La Veu de Tortosa (53 núm. setmanals), La Veu Comarcal (48 núm. setmanals), Ara (272 núm. diaris), Vida Tortosina (373 núm. setmanals), Acció (27 núm. quinzenals), Lluita (14 núm. setmanals), Germanor (57 núm. bimensuals), La Santa Cinta (35 núm. mensuals), La Zuda (217 núm. mensuals). Emprarem una metodologia descriptiva i valorativa, mitjançant una anàlisi del discurs de les notícies aparegudes en els esmentats rotatius.

Els objectius d'aquest article són:

a. Conèixer a quin tipus de dona s'adreçà cada publicació escrita en català a Tortosa durant el primer terç del segle xx i saber si hi havia diferències en funció de la ideologia del rotatiu.

b. Saber quan es parla de la dona com a tema, per exemple, sobre la seva formació, i si hi ha diferències en relació amb la ideologia de la publicació.

c. Saber en quin moment la dona tortosina va prendre la paraula en la premsa comarcal en català i quins foren els seus interessos.

La nostra hipòtesi és que tots els redactors i col-laboradors de la premsa comarcal tortosina de l'època foren homes i la participació femenina fou pràcticament inexistent a principis de segle, i que cal esperar als anys 30 per trobar la intervenció de la dona, en un paper molt secundari, en la premsa catalanista de Tortosa.

Finalment, cal dir que existeixen diversos estudis amb relació a la implicació de la dona amb el catalanisme polític (Duch, 2013; Gonzàlez, 2006) i amb el sufragi femení (Carré \& Llinàs, 2008; Martín, 2013) en què de manera més o menys indirecta es parla de la premsa catalana que va cedir la paraula a la dona, però mai fins ara s'havia estudiat en relació amb la premsa en català de Tortosa. Així, per exemple, Antònia Carré i Conxa Llinàs tracten el feminisme del segle xx a Catalunya i quines foren les veus més significatives pel que fa a la conquesta del vot femení. Carré \& Llinàs (2008) i Aguilera (2014) també es refereixen a les Seccions Femenines que es van fundar en els partits polítics més rellevants del moment, sobretot la Lliga i ERC, i de com van anar creixent entre 1932 i 1936. I Julià Guillamon reconstrueix la història de l'escriptora i periodista d'esquerres Rosa Maria Arquimbau i les seves col-laboracions en diverses publicacions com Joventut catalana, Lletres catalanes, Flama Nova, L'Estudiant, La Rambla, L'Opinió, etc.

\section{La dona com a tema en la premsa tortosina (1900-1936)}

\subsection{La Veu de Tortosa, La Veu de la Comarca i el Bolletí}

La premsa escrita en català a Tortosa durant els dos primers decennis de segle s'adreça a la dona tortosina de pensament conservador i burgès, que feia prevaldre les virtuts de la discreció, el pudor i la disciplina espiritual com a devota.

Cal que hi pensem en tot això les dones de Catalunya, i que donem al nostre feminisme una tonalitat de discreció, de pudor, filla d'una sensibilitat depurada que en res perjudicarà la capacitació cívica i intel-lectual que ens procurem, i que serà tant més intensa quan més disciplinades siguen espiritualment. Aleshores, 
com vol l'Apel-les Mestres i com deia el plorat Torres i Bages, la dona vencerà els obstacles que s'oposin al seu camí per la gracia d'una culta feminitat. (LVT 13, 30VIII-1930, p. 3).

Com ja es desprèn de LVT (1899-1902), l'assistència femenina a actes i conferències a Tortosa és merament decorativa, «senyoretes que donen una nota simpàtica a l'acte». I si la dona té formació intel-lectual -sobretot artística- aleshores es parla de «dames i donzelles catalanes». Quan s'al-ludeix a la dona treballadora es fa des d'aquesta mateixa perspectiva: «Avui celebrem la diada de la seva Patrona, santa Llúcia, les "modistetes belles i gentils" de la nostra ciutat (...) Els desitgem que tot els vagi be i que amb l'alegria que elles reparteixin pels nostres carrers, hi ajuntin la simpatia que nosaltres sentim per elles» (LVT 28, 13-XII-1931, p. 4).

Pel que fa a les manifestacions de catalanisme, la dona assisteix a aplecs, participa en les seccions de senyoretes dels centres excursionistes i dels orfeons catalans i col-labora en iniciatives com la de confeccionar una senyera per a la Unió Catalanista (LVT, 1899-1902). Cal assenyalar, d'altra banda, que la dona catalana ${ }^{7}$ havia entrat de ple en el nacionalisme, o millor dit, en les manifestacions nacionalistes, com es ressenyava a La Renaixença sobre el míting de Berga (LVC 92, 8-x-04, p. 2-3). S'hi citen com a exemples l'escriptora Agnès Armengol de Badia, qui dirigeix la iniciativa de regalar una bandera catalana a la Unió Catalanista, o Maria Marpeu i Buxareu de Campà, que cedeix el Pi de les Tres Branques a la Unió. També a Tortosa es demana la implicació de les «dones tortosines» a col·laborar en la realització de la bandera, a participar en les activitats del Centre Excursionista o a contribuir amb una subscripció a la festa del 20 de maig de 1906 a Barcelona.

El col-laborador Dertusà anima la dona tortosina a participar en un concurs de targetes postals que havia organitzat el Centre Excursionista de Tortosa -dirigit per Joan Abril, director també del setmanari La Veu de la Comarca- (LVC 107, 21I-1905, p. 2). D'aquí naix la idea de crear una secció de senyores excursionistes dins d'aquesta societat, com ja existia a Barcelona i en altres pobles de Catalunya. I en la secció «Notícies» del mateix número, es fa referència a l'entreteniment majoritari de les noies benestants quan es reunien en la casa d'alguna modista per aprendre a cosir i per fer-se l'aixovar, mentre les mares els feien els vestits per anar als balls del Centre Excursionista, a la vegada que s'anima la dona tortosina a participar en activitats culturals i artístiques organitzades per l'esmentada societat:

Molt visitada ha estat durant la setmana la exposició de tarjetes postals establerta en l'hostatje del Centre Excursioniste, en particular lo diumenje per la tarde y vespre que estaba ple de tortosins y xamoses tortosines entre les que reynaba el entusiasme patri fins á iniciarse en un grupo d'elles lo pensament que al igual que á Barcelona y altres pobles hi hagés també secció de excursionistes de sinyores, quin pensament no deixaría de tenir seguidores, ja que sembla son tres los plecs presentats al concurs de postals fets per senyoretes. Molt mes curt

7 La dona catalana a la qual es refereixen en relacionar-la amb el nacionalisme és la dona burgesa, de classe benestant, però no la dona treballadora. 
y aprofitós es lo folklorisme que no el ball y la tertulia de «estisora» ja siga en escursions ja en estudis historics, ó trevalls artistics com es dedicarse á la musica, al dibuij, pintura y cant; en prengin dons tan hermós y honrós camí, que no'ls faltarán admiradós y ajudans en tan patriótica i noble tasca. (LVC 107, 21-I-1905, p. 2-3)

\subsection{Vida Tortosina}

Mitjançant la revista Vida Tortosina coneixem un altre tipus de dona, més conscient de la realitat historicopolítica del moment i més compromesa amb la causa catalana. És la que respon al crit de Francesc Macià perquè donés suport a l'Estatut de Núria com a agent social, encara que ella no pogués votar. De fet, la resposta fou general a tot Catalunya i s'hi va crear el Comitè Pro Estatut d'Autonomia, amb un missatge ben clar: «Dones catalanes, el vostre deure, en aquest moment, és fer votar l'Estatut i signar les fulles del plebiscit femení» (Vallès, 1977: 88). D'altra banda, també se li demanava que participés en la campanya per l'alliberament dels presos polítics catalans de la Dictadura tot signant-hi un manifest (Vida T. 137, 5-IV1930, p. 2). En l'article 20 del títol III de l'Estatut interior de Catalunya, del 25 de maig de 1933, es reconeix el dret al vot de les dones catalanes: «La Llei regularà l'exercici del sufragi sobre la base de la igualtat entre els sexes i determinarà les incapacitats i incompatibilitats per a ésser Diputat» (Pitarch, 1977: 453). I Vida Tortosina és testimoni de l'ingrés de la dona en la vida pública, com a votant i com a treballadora, amb independència de l'home.

Segons Antònia Carré i Conxa Llinàs (2008), la desconfiança sobre el comportament que tindrien les dones a l'hora d'anar a votar va desembocar en el rebuig del sufragi femení entre els partits Radical, Radical Socialista i d'Acció Republicana en les eleccions generals de 1933. En canvi, els partits conservadors, com ara el Partit Agrari o la Lliga Regionalista l'afavoriren, convençuts del suport de les dones al pensament i les polítiques de la dreta (Carré \& Llinàs, 2008: 143). L'article 36 de la Constitució espanyola els reconegué el dret al $\operatorname{vot}^{8}$. ERC i la Lliga van veure aleshores la necessitat de fundar seccions femenines en els seus partits per tal de controlar un electorat nou que mai no havien tingut en consideraciós:

La primera vegada que les dones de l'Estat espanyol van participar en una consulta electoral va ser en el plebiscit per l'Estatut d'Autonomia d'Euskadi, el 1933 [...] En les eleccions generals hi hagué un total de tretze candidates catalanes, xifra relativament important si es té en compte que en les posteriors eleccions de 1936 no se'n va presentar cap (Carré \& Llinàs, 2008: 159).

8 La victòria fou de les dretes, essent aquesta ben àmplia a Espanya. A Catalunya, la Lliga Catalana aconseguia els seus millors resultats dins la República, mentre que la coalició AC-PNRE o les candidatures de BOC i PSOE van ser un fracàs. Segurament el vot femení, i en especial el catòlic, tingué la seva repercussió en aquest triomf dretà.

9 Finalment, però, les catalanes no van poder votar en les primeres eleccions al Parlament de Catalunya, amb l'excusa de no haver pogut confeccionar el cens femení reformat. 
D'altra banda, podem parlar d'un nou enfocament en Vida Tortosina respecte a altres rotatius escrits en català, la major part dels quals dedicava les seccions femenines a temes com la cuina o la moda, com en La Veu Comarcal i, posteriorment, en el diari Ara. Com diu F. Comas, en l'article "Pel redreçament de la dona», es tractava d'un moment en què la dona ingressava en la vida pública, ja fos sota l'aspecte social, jurídic o polític -arran de la majoria d'edat que, com a votant, adquiria a partir de les eleccions generals de 1933, com també en treballs que podien proporcionar-li un mitjà de vida independent de l'home. I per això mateix, es queixava que en els diaris i les revistes en què hi havia una pàgina o secció adreçada a la dona, aquesta estigués dedicada a parlar de temes banals:

[...] S'hi exposa exclusivament sobre bellesa, amor i dites que lluny de contribuir al seu perfeccionament intel-lectual, el que fan és malmetre'l degut al gust poc refinat que tenen generalment [...] Deixem-nos d'aquests passatemps que no porten a cap resultat pràctic i posem-nos més a to amb el moment actual, deixem de jugar amb la paraula «amor», guardem per la intimitat tot el romanticisme que porta i donem publicitat a les diferents manifestacions a l'ordre del dia, en què la dona pot actuar-hi. (Vida T. 301, 3-vI-1933, p. 6).

Una altra qüestió que sobresurt a Vida Tortosina és la insistència en la necessitat d'educació i d'instrucció per a la dona. Així, Maria Rosa, en «Temes femenins: La dona deu ésser feminista», defineix el terme feminisme i el considera sinònim de «llibertat» i de «consciència», per a les quals cal instrucció:

La dona feminista no és, tanmateix, una dona donada de ple, exclusivament, a certa lectura que li permeti el luxe d'ostentar el qualificatiu pompós d'intel-lectual. Feminisme, no vol dir, ni pretendre situar-se en un nivell superior al seu sexe oposat, ni a consolar-se a viure sota el seu jou; feminisme, és altra cosa infinitament més bella, més noble i més útil. Vol dir llibertat, i consciència; instrucció. Ésser feminista, no és masculinitzar-se. La dona feminista, és una dona que es fa càrrec de la seva responsabilitat, que es sent femenina abans que tot $i$, per tant, que comprèn quina és la seva sagrada missió en aquesta vall de llàgrimes (Vida T. 113, 10-x-1929, p.14).

I, en especial, s'insisteix a educar i formar la dona camperola (Escola rural). Així, la mestra nacional Carme Martorell i Viladrich explica, en la conferència «Educació de la dona per a fer agradosa i atractívola la vida del camp», organitzada per l'Ateneu Tortosí dins la Setmana Agrícola, com havia de ser l'educació que havia de rebre la dona per a complir la seva missió social. Segons el seu parer, «cal intensificar l'actuació de l'escola rural per formar la dona camperola, amb la qual cosa s'evitaria molta de l'emigració de la gent del camp», i posa com a exemple d'educació post escolar, la Granja-Escola de Loeken (Bèlgica) i la Rinovata de Milà, entre altres (Vida T. 177, 17-I-1931, p. 7-8).

També Ferran Farran, en la secció «Agricultura», tracta el tema de la dona de camp i sol-licita instrucció per a la dona ebrenca, ja que la massa camperola vivia en un ambient d'ignorància en higiene, alimentació i agençament de la casa, que 
tant influïen en la salut i el benestar (Vida T. 354, 9-vi-1934, p. 27-28). Mentre que Josep Bòria, a «Suggerències i realitats» (Vida T. 354, 9-VI-1934, p. 29-31) es limitava a cantar les excel-lències de la dona catalana $i$, en concret, les de la dona pagesa del Baix Ebre.

Pel que fa a Vida Tortosina, cal destacar el fet d'haver-hi unes poques col-laboradores tortosines que prenen la paraula $i$ signen els seus escrits, com són Maria Rosa, Amanda Llebot i, sobretot, Rosa Llambrich, la qual s'encarrega de la secció «Per la dona». Aquesta secció, apareguda des del núm. 253, consisteix en un seguit de consells i recomanacions, proverbis i gasetilles adreçades a la dona, o que parlen de la dona, sovint en clau d'humor. Interessa remarcar aquí que una de les recomanacions de Rosa Llambrich a les dones era «que llegissin llibres en català» (Vida T. 299, 20-v-1933, p. 8).

Altres col-laboradores només intervenen en el número extraordinari que la revista va dedicar a la dona (Vida T. 354, 9-vI-1934, p. 1-44), com M. Cinta Balada, de Palestra. I no hem d'oblidar les aportacions literàries de la poetessa local Josefina Jardí i Codina o de Maria Llaó Martí (Montserratina).

Finalment, cal dir que la campanya duta a terme per Vida Tortosina sobre un curs d'alimentació i pràctiques de cuina, dirigit per Concepció Ferran i executat per Joan Vila, durant el 1934, va derivar en l'edició d'un número extraordinari de 44 pàgines dedicat a la dona, com ja s'ha dit. Amb el títol «Concepte de nutrició» (Vida T. 354, 9-VI-1934, p. 19), es publiquen en la revista un seguit d'articles a càrrec de Concepció Ferran, directora de la Secció d'Ensenyament Domèstic de la Generalitat, sobre "alimentació», arran del curs de cuina esmentat. I una altra secció apareguda a Vida Tortosina a partir d'aquest número extraordinari és «Culinàries» (Vida T. 354, 9-vi-1934, p. 25-26) en què es publiquen alguns dels consells, fórmules i receptes que el professor Joan Vila havia exposat en les lliçons del curset.

\subsection{La Veu Comarcal}

Pel que fa al setmanari La Veu Comarcal i al diari Ara, cal dir que es tornava a parlar de la dona conservadora i catòlica, que tenia com a virtut la caritat cristiana, i que es compadia dels pobres, és a dir, aquella que pertanyia a una classe social acomodada i es recordava dels més desvalguts. Així, per exemple, les modistes de la ciutat celebraven per Santa Llúcia un acte de caritat, tot recollint almoines per a una institució benèfica de Tortosa; per Nadal, les dones de la Secció Femenina de la Lliga Republicana Comarcal ${ }^{10}$ repartien bosses de queviures entre els més desemparats i, per Cap d'Any, servien un dinar als asilats de 1'Hospital de Santa Creu.

10 La Secció Femenina de la Lliga Comarcal Republicana seguí l'exemple de la Secció Femenina de la Lliga Regionalista, dirigida per Francesca Bonnemaison, vídua de Verdaguer i Callís, a instàncies de Francesc Cambó. El primer local de la Secció Femenina de la Lliga es fixava en el seu domicili particular, el 1932. El 1933 ja hi havia 30 seccions femenines a Catalunya; mentre que el 1935 la Lliga Catalana ja en tenia 85, gràcies a la capacitat organitzativa de Francesca Bonnemaison. Les dones d'ERC també van tindre'n des de 1932 i, posteriorment, formaven el Front Únic Femení Esquerrà. El Bloc Obrer i Camperol, l'organització comunista més important a Catalunya fins a 1935, també en va endegar des del mateix any (Carré \& Llinàs, 2008: 158). 
En les eleccions generals de novembre del 1933, quan el vot femení es duia a la pràctica per primera vegada, la dreta va guanyar els comicis, de la qual cosa es responsabilitzà el vot femení, majoritàriament conservador. Els arguments de la Lliga foren la defensa de la religió, l'ordre i la tranquil-litat de la llar. «El sufragi femení va ser el boc expiatori de molts errors comesos per l'esquerra» (Carré \& Llinàs, 2008: 160).

Per a Gemma Aguilera (2014: 553-554), el catalanisme integrà la dona amb un doble discurs justificatiu a partir de la legalització del sufragi femení:

S'engrossirà amb una nova entrada de militants que, alhora, exerciran el paper de transmissores i de garants de la supervivència dels elements identitaris com la llengua, la cultura, i fins i tot, la religió. El catalanisme segueix el model d'altres moviments nacionalistes europeus contemporanis, si bé, temerós d'un progressiu avenç femení cap a la igualtat real, estructurarà la participació femenina de manera que només sigui un complement als homes del partit. La separació es perpetrarà entre 1932 i 1936 amb la creació de les seccions femenines dins dels principals partits catalans. Aquesta segregació, consentida i aplaudida per les dones d'ERC, la Lliga Regionalista, el Bloc Obrer i Camperol, el PSUC, el POUM i també les Joventuts d'ER-Estat Català (...), les mantindrà en segon pla, dedicades a convèncer les seves conciutadanes, els marits i els fills de les virtuts del catalanisme. La voluntat de fer veure a la dona que la divisió social i política entre sexes és positiva i encertada serà transversal a tot el catalanisme, si bé els partits progressistes matisen el seu discurs tot dignificant les feines femenines.

Els arguments d'ERC per atraure el vot femení van ser -segons Carré i Llinàsels drets aconseguits durant la Segona República: el divorci, el sufragi, la millora del sistema educatiu, la Llei de l'assegurança de maternitat, l'abolició de la distinció entre fills legítims i naturals, etc.; mentre que els arguments de les dones conservadores de la Lliga eren la defensa de la religió, l'ordre, la tranquil·litat de la llar ${ }^{11}$, etc.

Com ve es diu en l'editorial «La festa de demà. Patriotisme és caritat» (LVComarcal 31, 29-XII-1934, p.1) en relació amb la Festa del banderí, els ideals superiors per a les dones de La Veu Comarcal, conservadores i catòliques, són Déu i Pàtria. "La festa de demà té, doncs, per nosaltres, fervents creients i entusiastes patriotes, una significació i la delícia encantadora que no podria lograr mai dins el camp d'una política laica». I en l'article, sense signar, de «La significació del banderí» (LVComarcal 31, 29-xII-1934, p.1), cal interpretar la subjugació de la dona respecte a l'home com una altra de les seves «virtuts» cristianes; a més, hom l'equipara a la dona idealitzada dels trobadors:

Des de demà ja tindreu un Banderí, homes joves de la Joventut de Lliga Comarcal Republicana de Tortosa! Mans blanques de gaies nines el brodaren, el pensament posat en vosaltres, com antany teixien el lli i brodaven les sedes amb

11 A les eleccions municipals de 1934 es van presentar per primera vegada dues dones a les llistes de la Lliga: Francesca Bonnemaison i Montserrat Serres; la llista, però, no fou elegida. 
l'or de la il-lusió darrera les gelosies dels castells aquelles princeses dels contes de fades, somniant amb ardits prínceps i gentils trovadors que en el camp de l'honor i de la poesia enriquien la Pàtria amb ses gestes audaces i sos cants deliciosos d'amor i d'esperança. I vosaltres el rebreu, cavallers d'un ideal, per passejar-lo triomfant per totes bandes com els il-lustres herois de les llegendes -Sant Jordi davant tot- alçaren penons i senyeres envolcallant-les de la glòria conquerida en les lluites per la Fe i per la Pàtria.

A partir de gener de 1935, amb la renovació i l'ampliació del setmanari, hi apareix una nova secció amb el títol «Feminisme», encapçalada per un manifest escrit en lletra majúscula on es fa referència al vot electoral femení i a la dona catalana tot al-ludint al seu paper en relació amb el catalanisme conservador del primer decenni del segle (aquelles damisel-les que brodaren la bandera catalana per a la Unió Catalanista, o la cessió del Pi de les Tres Branques, símbol de Catalunya, etc.). La secció va adreçada a la mestressa de casa, acomodada, amb continguts com: la moda, detalls i accessoris; labors; receptes de cuina i menús del diumenge, presentació de la taula, etc. Hi havia, però, una altra novetat i és el fet que la dona tortosina prenia la paraula en primera persona tot signant els seus articles, com també succeïa a Vida Tortosina. Per exemple, la poetessa Isabel Rodés de Cardoner hi endega la secció «Escriptores catalanes» (LVComarcal, 46, 18-IV-1935, p. 3); Maria Neus parla de la diada de Sant Jordi a «Pàtria i cultura» (LVComarcal, 48, 27-IV1935, p. 3); i Cecília hi escriu una dissertació sobre l'home i la dona, reflex del seu pensament catòlic: «És precís l'esforç de la dona que amb l'arma de la virtut ha de lluitar pels drets de la llar i per les prerrogatives del Temple» (LVComarcal, 48, 27IV-1935, p. 3).

Finalment, Joan de Caro, en l'article «Feminisme actiu» (LVComarcal, 48, 27-IV1935, p. 3), s'adreçava a la dona conservadora a fi que s'impliqués en la política i donés el vot femení a la dreta, com ja havia succeït en les eleccions de 1933:

Avui l'acció de la dona no pot quedar reclosa a la llar perquè aquest és el mirall del carrer, i rep les sotragades de les passions revolucionàries. En la Setmana Tràgica i en els Fets d'Octubre de 1934 la dona jugà un paper reeixit. Que ningú pense -diu- que la tragèdia ha acabat a Espanya. La revolució d'Octubre va ésser sols l'inici. I no trigarà a rebrotar amb major pujança si un feminisme actiu intensament practicat no posa un fre immediat a la malaurada tendència soviètica de les nostres forces socials, obreres i també de la classe mitjana.

\subsection{Ara}

La dona a la qual s'adreça aquest rotatiu és la dona catòlica, model de virtuts cristianes per als fills, amb formació artística, que pertany a la classe social acomodada de Tortosa i que no treballa fora de la llar, és a dir, la mateixa de La Veu Comarcal. Així, Lluís de Montsià, en la secció "A vola ploma: La ràdio i el piano» (Ara 17, 18-vIII-1935, p. 1), es queixa que moltes professores de piano han hagut d'abandonar la professió perquè -diu- les «senyoretes» prefereixen quedar-se 
a casa amb la ràdio. L'autor de l'article defensa la formació artística de la dona, que toqués el piano i sabés dibuixar: «Si la mare no sent l'art, quin sentiment pot infondre cap al seu fill?».

El rotatiu descriu diversos actes duts a terme a la ciutat en relació amb la caritat cristiana de les dones tortosines: donatius de la Confraria de la Cinta per als reclosos de la presó; recaptació benèfica de les llucietes destinada a l'Hospital (Ara 107, 10-XII-1935, p. 3); Festa del banderí a càrrec de la Secció Femenina de la Lliga Comarcal Republicana; donatius en metàl-lic d'Acció Catòlica per a les Germanetes dels Pobres, menjador dels pobres, presó i hospital, i distribució de joguines i de roba per als nens el dia de Reis (Ara 118, 22-xII-1935, p.1). La secció «La Gota de Llet» de la Creu Roja reparteix a Tortosa durant el mes de desembre i de manera gratuïta 2.850 biberons (Ara 135, 15-I-1936, p. 3). I el 24 de maig de 1936 té lloc un festival taurí a benefici de la Creu Roja i de La Gota de Llet.

Al setembre de 1935 el diari Ara va inaugurar una nova secció que apareixia tots els divendres, anomenada «Secció Femenina», dedicada a la mestressa de casa, i de la qual s'encarregà Isabel Rodés de Cardoner. Aquesta tenia unes característiques molt semblants a la secció «Femenina» de La Veu Comarcal. Així, es parla de la moda i de la taula, en la subsecció «Cultura domèstica» (amb receptes gastronòmiques tretes del fitxer del professor Joan Vila), i va comptar amb col-laboradores diverses com Maria Rosa, amb «Consells a les amigues»; Greta, amb «La moda», o Cecília, amb «Suggerències», etc. $\mathrm{A}$ «Consells a les amigues: La personalitat» (Ara 86, 15-XI1935 , p. 4), Maria Rosa aconsella les dones benestants perquè procuressin tenir una formació artística àmplia que els permetés mostrar una opinió argumentada, a la vegada que els aconsellava com s'havien de dirigir a la gent més humil:

Sigueu sempre sinceres amb vosaltres mateixes, i obreu amb rectitud de consciència, procureu entendre un xic de cada cosa, ja que si en una reunió, en la que vosaltres assistiu es parla de política, de música o de literatura, pugueu prendre-hi part sense fer el ridícul i, fins, si és precís, sostenir el vostre criteri ben argumentat:

Sigueu benèvoles al jutjar a les vostres amigues, i dures amb vosaltres mateixes. Tingueu molta dolçor amb el tracte de les gens humils, és la millor almoina que els hi podeu donar.

A l'Ateneu s'organitza el III Curs d'Ensenyament Domèstic, a càrrec del professorat del Dept. de la Generalitat, dirigit per Concepció Farran -la qual havia dirigit també el curs d'alimentació organitzat per Vida Tortosina l'any 1934- i la professora de la secció és la senyoreta Núria Armangué (Ara 225, 6-v-1936, p. 2).

Finalment, i com a anècdota, recollim la informació apareguda dins la «Secció Femenina» del núm. 249, en què s'explicava que l'actriu cinematogràfica Mae West féu circular una llista de les faltes comeses per un gran nombre de dones i que anomena «Els set pecats capitals de la dona» (Ara 249, 5-VI-1936, p. 4):

Pintar-se la cara i els llavis en la taula d'un restaurant.

Preguntar-li al marit d'on ve.

AsparkíA, 32; 2018, 95-112 - ISSN: 1132-8231 - DOI: HTTP:/ / DX.DOI.ORG/10.6035/AsPARKIA.2018.32.6 
Fer-lo esperar en una cita.

Fer-li moixanes quan està de mal humor.

No fer-li moixanes quan està malalt.

Exhibir-se davant d'ell mal vestida o desarreglada.

Parlar dels seus admiradors.

\subsection{Lluita}

En el setmanari Lluita trobem la dona treballadora i d'esquerres de Tortosa, és a dir, la que no viu condicionada per la moral de l'Església, ni es limita a fer caritat amb els més desvalguts, com hem vist amb les tortosines benestants dels rotatius de la dreta catalanista com LVT, LVComarcal o el diari Ara. Ara es tracta de la dona que lluita per la justícia social, pels drets dels treballadors i les treballadores, que es compromet políticament i sindical i s'implica en els problemes socials dels seus companys i companyes obrers, que assisteix als mítings i va a la vaga a fi d'aconseguir la millora de les condicions del treball o dels jornals, que organitza $i$ participa en actes polítics en favor d'alguna causa, com la dels milicians del front, etc. La dona de Lluita no és, doncs, la dona pagesa, més conservadora i menys implicada en un nivell polític i social que la dona obrera.

Per a Assumpció Ramírez, en «La perfecció, fonament del socialisme» (Lluita 4, 30-v-1936, p. 2), la dona socialista és més lliure que la dona catòlica a l'hora d'escollir les seves lectures. Així, mentre que la dona catòlica refusa llegir llibres contraris al seu pensament, i sent remordiment de llegir coses que no haguessin passat per la censura dels seus directors espirituals, ella, com a socialista, té la llibertat de llegir de tot per convèncer-se de la perfecció de les idees socialistes: «Doncs bé, aquesta lluita moral que et provoquen les idees contràries a les teves és la causa de la teva manca de fe -tu llegeixes i a mida que vas llegint medites, penses... i veus i comprens que les teves idees careixen de fonaments prou ferms per evitar que es bambolegin a la més lleu trontollada. Però tu això no ho vols confessar».

En l'article «Les dones a la lluita» (Lluita 10, 11-vII-1936, p. 3), sense signar, hom argumenta que des que la dona havia participat de forma activa en els darrers comicis, el camí estava més assaonat de justícia social:

Dóna bo de veure anant per aquestes contrades de Catalunya com la dona, cada dia amb major proporció, acudeix als actes, siguin de la propaganda que siguin, i escolta atentament, subratllant amb forts aplaudiments tot allò que blasma les iniquitats i les injustícies de les castes imbuïdes de superioritat mal entesa i que els seus instints morbosos voldrien subjugar les multituds productores a les seves concupiscències en benefici dels menys i en perjudici dels més.

En els mítings, especialment en els dels partits de classe, es vol escoltar la dona oradora; arreu se sent la necessitat i la curiositat d'escoltar-la: «No és necessari que les companyes oradores portin un gran bagatge d'oratòria floralesca, sinó que amb llur proverbial sencillesa diguin i expressin allò que realment senten, puix 
que el poble el llenguatge que va del cor als llavis és el que millor entén». I només amb l'anunci d'una oradora a qualsevol míting, hom s'assegura que la meitat dels oients siguen dones: «llur paraula és àvidament escoltada i gairebé sempre millor compresa, puix que la dona del poble posa més fe de veracitat al que diu una companya, que no a l'expressió fàcil quasi sempre dels homes», com s'exposa en l'esmentat article (Lluita 10, 11-viI-1936, p. 3). Així, doncs, la intel-ligència emotiva de l'oradora connecta molt millor amb les assistents als actes que no pas els homes.

Fet i fet, iniciada la tercera setmana de la vaga del ram tèxtil, davant la inhibició del problema per part de l'alcalde Berenguer, la intransigència de la patronal i les intervencions tènues del delegat de Treball, es duu a terme un nou míting de suport al ram en el Cinema Doré, on la dona tortosina demostra que és al capdavant contra l'explotació burgesa, amb les oradores Amparo Martí, Josefina Roca, Magda Salvans i Ángeles Jardí (UGT), juntament amb Tomàs Verdal (UGT) -director del setmanari-, Juan Forés i Josep M. Cano (CNT). Amparo Martí és la presidenta del comitè de vaga. La patronal els havia ofert el 15\% d'augment dels sous, mentre que les treballadores en demanaven el 30 o 35\%, la qual cosa representava una millora modesta dels jornals -segons el rotatiu. Roca es queixa de l'excés de producció que se'ls imposava, i remarca la conducta dels encarregats, ajudants dels burgesos, en l'explotació de les treballadores. Salvans esmenta la manca de consciència i sentit humà dels patrons. Jardí explica l'actitud del fabricant Sanz quan es va adonar que les treballadores se sindicaven. Mentrestant, un grup de noies de la Joventut Socialista Femenina imposava un banderí per a recaptar fons entre els assistents en favor de les vaguistes. Acaba l'acte amb tots els presents dempeus entonant La Internacional i amb el puny enlaire (Lluita 11, 18-vII-1936, p. 1).

D'altra banda, l'Agrupació Femenina Socialista i l'Agrupació Femenina del Partit Republicà d'Esquerra organitzen dos actes polítics multitudinaris a la plaça de bous de Tortosa en profit dels milicians de la comarca que eren al front. Entre els oradors i oradores del primer míting, Francesc Cabanes (ERC) es dirigia als assistents amb aquestes paraules en relació amb les dones: «ja han sabut desfer-se de l'influència del confessionari i anar a les organitzacions polítiques i sindicals a lluitar al costat dels homes per la llibertat del poble» (Lluita 14, 17-viII-1936, p. 2).

Finalment, cal recordar que un grup important de dones va fer un pas més en la lluita i es varen allistar a les milícies. Tanmateix, aviat el Govern espanyol els ho va prohibir, amb el beneplàcit de les organitzacions femenines mateixes:

[...]gosadia que aviat és sufocada tant pels primers grups feministes com pel govern de la República de Francisco Largo Caballero. La tardor de 1936, l'executiu espanyol decretà la prohibició d'allistament de dones a les milícies, de manera que la presència femenina a primera línia de foc només serà permesa en casos excepcionals. La decisió compta amb l'empara de la premsa, els partits polítics, els sindicats i les mateixes organitzacions femenines, que difonen el lema «homes al front $\mathrm{i}$ dones a la rereguarda", amb l'argument de la incapacitat militar de la dona i la seva predisposició a treballar a les indústries de guerra i en serveis d'assistència social (Aguilera, 2014: 556). 
Tot seguit presentem una taula a manera de resum sobre «La presència de la dona en la premsa tortosina en català»:

\begin{tabular}{|c|c|c|}
\hline Rotatiu & Ideologia & Característiques que es retraten de la dona \\
\hline $\begin{array}{l}\text { La Veu de } \\
\text { Tortosa (I) }\end{array}$ & $\begin{array}{l}\text { Catalanisme con- } \\
\text { servador (portaveu } \\
\text { regionalista, de dreta } \\
\text { i catòlic). }\end{array}$ & $\begin{array}{l}\text { Dona tortosina burgesa i conservadora. } \\
\text { Funció decorativa de les «senyoretes» que assisteixen a actes } \\
\text { i conferències, que donen una nota «simpàtica» a l'acte. } \\
\text { Assisteixen a aplecs catalanistes, orfeons catalans i altres } \\
\text { iniciatives del Centre Excursionista de Tortosa. }\end{array}$ \\
\hline $\begin{array}{l}\text { La Veu } \\
\text { de la } \\
\text { Comarca }\end{array}$ & $\begin{array}{l}\text { Catalanisme conser- } \\
\text { vador. Portaveu de } \\
\text { Solidaritat Catalana. }\end{array}$ & $\begin{array}{l}\text { Dona tortosina burgesa i conservadora. } \\
\text { Se li demana la participació en manifestacions nacionalistes } \\
\text { i activitats del Centre Excursionista. Naix la idea de crear-hi } \\
\text { una «secció femenina». }\end{array}$ \\
\hline Bolletí & $\begin{array}{l}\text { Catolicisme nacional- } \\
\text { catalanista (Torras i } \\
\text { Bages). Apolític. }\end{array}$ & $\begin{array}{l}\text { Dona tortosina burgesa i conservadora. } \\
\text { S'adreça a la dona devota. Posa l'interès en la instrucció i } \\
\text { l'educació religiosa de les dones catalanes. }\end{array}$ \\
\hline $\begin{array}{l}\text { La Veu de } \\
\text { Tortosa } \\
\text { (II) }\end{array}$ & $\begin{array}{l}\text { Catalanisme conser- } \\
\text { vador (de centre i } \\
\text { catòlic). Portaveu de } \\
\text { la Lliga. }\end{array}$ & $\begin{array}{l}\text { Tortosina burgesa i conservadora. } \\
\text { Funció decorativa de les «senyoretes». «Dames i donzelles } \\
\text { catalanes» quan tenen formació artística. } \\
\text { Virtuts de la dona devota: «discreció», «pudor» i «disciplina } \\
\text { espiritual». }\end{array}$ \\
\hline $\begin{array}{l}\text { La Veu } \\
\text { Comarcal }\end{array}$ & $\begin{array}{l}\text { Catalanisme conser- } \\
\text { vador (de dretes i } \\
\text { catòlic). Portaveu de } \\
\text { la Lliga Catalana al } \\
\text { Baix Ebre. }\end{array}$ & $\begin{array}{l}\text { Tortosina conservadora i catòlica. Mestressa de casa. } \\
\text { Es defensa: la religió, l'ordre i la llar. Ideals: Déu i Pàtria. } \\
\text { Virtut: «caritat cristiana» i subjugació a l'home. } \\
\text { Es demana la implicació política de la dona i el vot femení } \\
\text { per a la dreta. }\end{array}$ \\
\hline Ara & $\begin{array}{l}\text { Catalanisme conser- } \\
\text { vador (de dretes i } \\
\text { catòlic). }\end{array}$ & $\begin{array}{l}\text { Tortosina conservadora, catòlica i acomodada. } \\
\text { Virtut: «caritat cristiana». } \\
\text { Es defensa la religió i l'ensenyament catòlic privat. }\end{array}$ \\
\hline $\begin{array}{l}\text { Vida } \\
\text { Tortosina }\end{array}$ & $\begin{array}{l}\text { Moderat nacionalis- } \\
\text { me d'esquerres (no } \\
\text { regionalista). }\end{array}$ & $\begin{array}{l}\text { S'insisteix a educar i instruir la dona, en especial la campero- } \\
\text { la tortosina (Escola rural). } \\
\text { Es té consciència de l'ingrés de la dona en la vida pública, } \\
\text { com a votant i com a treballadora, amb independència de } \\
\text { l'home. } \\
\text { Primeres tortosines que prenen la paraula i signes els seus } \\
\text { escrits. }\end{array}$ \\
\hline Acció & $\begin{array}{l}\text { Nacionalisme d'es- } \\
\text { querres. Portaveu } \\
\text { d'ACR. }\end{array}$ & $\begin{array}{l}\text { No hi ha referències específiques a la dona. } \\
\text { S'informa sobre el curs d'alimentació impulsat per Vida T. i } \\
\text { dut a terme a l'Ateneu Republicà. }\end{array}$ \\
\hline
\end{tabular}

Font: elaboració pròpia. 


\section{Col-laboracions femenines en la premsa tortosina}

Pel que fa a intervencions femenines a La Veu de Tortosa ${ }^{12}$, cal dir que són molt esporàdiques. Hi destaquen la Sra. Agnès Armengol de Badia, amb el poema «¡Dorm!» (LVT 121, 16-III-1902, p. 3) i dos articles més: un és l'oferiment per a realitzar una senyera a la Unió Catalanista (LVT 22, 29-IV-1900, p. 2-3), i l'altre, on demana l'ajut a altres dones interessades a col-laborar-hi (LVT 24, 13-v-1900, p. 3). Quant a la participació literària, parlem de: un poema dedicat a la Verge de Montserrat de Sor Eulàlia Anzizu (LVT 74, 28-IV-1901, p. 4); Maria de Bell-1loch, amb «Á una Roquerola» (LVT 116, 9-II-1902, p. 3), i Enriqueta Paler i Trullol, amb un poema de condol per la mort de Jacint Verdaguer titulat «En la mort del nostre eximi poeta» (LVT 139, 20-viI-1902, p. 3). Tampoc no hi hagué col-laboracions femenines en el seu homònim de 1930-31 -amb l'excepció d'un article de Montserrat Jordi.

També són inexistents les colllaboracions femenines a $\mathrm{La} \mathrm{Veu}$ de la Comarca ${ }^{13}$ i al Bolletí de la Lliga Espiritual de la Mare de Déu de la Cinta, a excepció de minses aportacions poètiques foranes a LVC (Agnès Armengol i Sor Eulàlia Anzizu) i de l'article «A les dones catalanes» de Magda Martí (Torredembarra) al Bolletí, en què descriu com ha de ser la dona devota i on posa un interès especial en la instrucció i l'educació religiosa de les catalanes. Acaba el text amb les paraules següents: «Trevalla per Déu i per la Pàtria, dona catalana, i que les benediccions de la Mare de Déu de la Cinta siguin copsades per tots els bons fills de nostra terra, no menys pels que li preguen a prop de l'Ebre que pels que esguarden el cel des del Pirineu» (Bolletí 5, desembre 1919, p. 53).

Fet i fet, en general cal esperar als anys 30 per trobar col-laboracions femenines en la premsa tortosina en català, especialment a través de les seccions femenines, com la secció «Per la dona» de la revista Vida Tortosina, a càrrec de Rosa Llambrich, «Feminisme» del setmanari La Veu Comarcal i «Secció Femenina» al diari Ara, a càrrec de la tortosina Isabel Rodés de Cardoner. Tanmateix, trobem col-laboracions literàries en el cas de dues publicacions, com són La Zuda, revista cultural setmanal, i La Santa Cinta, nascuda com a revista mensual en commemoració del 750 aniversari del Descens de la Verge de la Cinta.

12 En relació als Jocs Florals de Barcelona de 1901-on la dama escollida esdevenia la reina de la festa-, $\mathrm{La}$ Veu de Tortosa insereix una ressenya de La Veu de Catalunya en què es descriu el guarniment de la sala de la Llotja i se'n relata l'acte, presidit per Pi i Maragall. Destaca el fet que, per primer cop, es va concedir un accèssit a la Flor natural a una dona, na Dolors Montcerdà de Macià; i també se li concedia un accèssit a la Viola d'or i d'argent pel poema «El plech de l'órfana».

13 LVC informa sobre l'aparició de Feminal, una revista mensual dedicada a la dona. Feminal es començà a publicar el 28 d'abril de $1907 \mathrm{com}$ a suplement mensual, dirigit per Carme Karr, del setmanari La Il.lustració Catalana. La revista fou una plataforma decisiva de promoció cultural per a les dones, un instrument d'expressió de l'alta burgesia catalana -molt lligada a la Lliga Regional-, que es va publicar fins a 1918. Un any abans, des de les pàgines de Feminal, es reclamava el vot de les dones (Carré \& Llinàs, 2008: 165). 


\subsection{La Zuda (1913-1933)}

En el núm. 100 (octubre de 1921) apareix la primera col-laboració femenina en català, de la mà de Magda Martí: «Re femenina. La dona es lo mes bell amb que Deu orná la terra». La secció «Nostres poetesses» és inaugurada per Maria Fonts Soler (tortosina d'adopció) al mes de maig de 1924, la qual aporta al voltant d'una dotzena de composicions poètiques fins a 1932, com: «A les montanyes del Port» (La Zuda 124, gener 1924, p. 5); «La mort d'un nin captaire. Quadre d'hivern» (La Zuda 128, maig 1924, p. 74); «Excelsitud» (La Zuda 129, juny 1924, p. 91); «No temèu a la mort» (La Zuda 130-131, agost 1924, p. 119); "Aires de la serra» (La Zuda 134, novembre 1924, p. 160); «Mística ferida» (La Zuda 136, gener 1925, p. 6); "A un mal marit» (La Zuda 139, abril 1925, p. 67); «Nocturn» (La Zuda 142, juliol-agost 1925, p. 93); «Al mar», "A la neu» (La Zuda 148, març 1926, p. 46); "A la Verge de l'Aldea» (La Zuda 172, juny 1928, p. 87) i «La volada d'un infant» (La Zuda 216, desembre 1932, p. 117).

I la barcelonina Josefa Rosich Cotuli hi colllaborà amb: «Ànsies eternes» (La Zuda 153, agost-setembre 1926, p. 166); «El cant de la inmesitat» (La Zuda 156, desembre 1926, p. 220); i «La bondad» (La Zuda 163, setembre 1927, p. 121); a més d'altres aportacions pòstumes com: «La corona» (La Zuda 168, febrer 1928, p. 29); «Cantinel-les» (La Zuda 169-170, març-abril 1928, p. 53); «El prodigi de la Cinta» (La Zuda 174, setembre 1928, p. 124); «Fantasia primaveral» (La Zuda 180, abril 1929, p. 42-43) i «La Verge profanada» (La Zuda 181, maig 1929, p. 59). Finalment, Isabel Rodés de Cardoner, ho fa amb «Maig» (La Zuda 192, juny 1930, p. 74).

\subsection{La Santa Cinta (1928-1936)}

Les aportacions femenines a La Santa Cinta són: Josefa Rosich Cotulí: «A Tortosa. Cançó de bressol» (Sta. Cinta 2, febrer 1928, p. 14); «A Tortosa. La Santa Cinta Universal» (Sta. Cinta 5, maig 1928, p. 61). Maria Fonts Soler: «Un misteri indefinit» (Sta. Cinta 3, març 1928, p. 29); «A la mare de Déu de la Cinta» (Sta. Cinta 24, desembre 1932, p. 4); i «La diada de la Cinta i les campanes de la Seu» (Sta. Cinta 30, setembre 1934, p. 16). Carmen Rochar (Tortosa): «Contalles d'un mare» (Sta. Cinta 24, desembre 1932, p. 7). I Isabel Rodés de Cardoner: «Sancta Maria, ora pro nobis» (Sta. Cinta 24, desembre 1932, p. 11); i «Aubada» (Sta. Cinta 28, març 1934, p. 7).

\section{Conclusions}

La dona tortosina que es reflecteix en la premsa conservadora escrita en català durant el primer terç del segle xx s'adiu amb la dona burgesa i catòlica, que participa en aplecs i actes catalanistes com a simple observadora. També entre aquesta premsa conservadora trobem les seccions femenines dedicades exclusivament a temes banals i adreçades a la dona benestant, model de mestressa de casa -després de veure els resultats electorals de 1933, és quan es demana que la dona intervingui 
en política com a votant ( $\mathrm{La}$ Veu Comarcal). Així, doncs, podem dir que coincideix amb el discurs de «la domesticitat» de què parlen Antonia Carré i Conxa Llinàs en referir-se al «feminisme conservador» ${ }^{14}$.

D'altra banda, hi ha la dona més compromesa amb la causa catalana, com és la de Vida Tortosina, que dóna suport a l'Estatut d'autonomia i a Francesc Macià, o que fa campanya per l'alliberament dels presos polítics catalans. Tanmateix, tot i ser votant d'ACR, sovint encara es troba lligada per la influència del confessionari i de la classe benestant.

Finalment, hi ha la dona tortosina de Lluita, compromesa amb la seva realitat historicosocial, que representa la defensa de la justícia social i contra l'explotació burgesa, i que sap anar a les organitzacions polítiques i sindicals a lluitar al costat dels homes per la llibertat del poble. Així, doncs, el concepte de dona que s'infereix des de Lluita no té res a veure amb la mestressa de casa de les publicacions tortosines emparentades amb el catalanisme conservador, ni amb el moderat nacionalisme de Vida Tortosina. Podem dir que és un reflex del «feminisme progressista», que recollia les lluites per la igualtat a través del socialisme, l'anarquisme i el sindicalisme, al qual es referien les autores esmentades anteriorment.

Totes tres dones tortosines - la conservadora, la nacionalista i la sindicalista ${ }^{15}$ coincideixen a ocupar un segon pla respecte a l'home en el terreny polític -amb l'empara dels partits i de les organitzacions femenines mateixes-i la seva presència en la premsa comarcal escrita en català a Tortosa és gairebé testimonial. En general, cal esperar als anys 30 per trobar-hi col-laboracions femenines, especialment a través de seccions femenines a Vida Tortosina, La Veu Comarcal i el diari Ara. Finalment, i pel que fa a aportacions literàries, trobem que La Veu Comarcal, 1'Ara, La Zuda i La Santa Cinta actuen com a plataformes de difusió de poetesses catalanes, en especial de Maria Fonts Soler, Isabel Rodés de Cardoner i Josefa Rosich Cotuli.

\section{BIBLIOGRAFIA}

Aguilera, Gemma (2014): «Dones independents, de la reraguarda a la trinxera» en GonzÀlez i Vilalta, Arnau; López Esteve, Manel i Enric Ucelay-Da CAL (eds.) (2014). 6 d'Octubre. La desfeta de la revolució catalanista de 1934, Barcelona: Editorial Base, pp. 553-565.

CARré, Antònia \& Llinàs, Conxa (2008): Les dones tambéfem democràcia. 75è aniversari del vot femení a Catalunya, Barcelona: Raval Edicions SL «Mina-Temps».

Duch Plana, Montserrat (2013): El gènere de la polis. La trajectòria de les dones en el catalanisme politic, Tarragona: Arola Editors, pp. 33-59.

GonzÀlez i Vilalta, Arnau (2006): La irrupció de la dona en el catalanisme, 1931-1936: introducció i selecció de textos, Barcelona: Publicacions de l'Abadia de Montserrat.

$14 \mathrm{Amb}$ veus com Dolors Monserdà, Carme Karr i Francesca Bonnemaison, les quals s'expressaren a través de revistes i diaris com La Veu de Catalunya, La Renaixença, Il-lustració Catalana, D'Ací i d'Allà, Acción Católica Femenina, La Ilustración de la Mujer, Joventut, Feminal, etc.

15 A Tortosa no podem parlar de la dona d'ERC perquè no hi existí cap òrgan periodístic que el representés fins a 1937, amb El Poble. 
Guillamon, Julià (2015): L'enigma Arquimbau. Sexe, feminisme i literatura a l'era del flirt. Barcelona: Ed. Comanegra, pp. 87-311.

MARTín I Berbois, Josep Lluís (2013): Ignorades però desitjades. La dona política durant les eleccions de la Segona República a Catalunya, Barcelona: Acontravent Generalitat de Catalunya.

Pitarch, Ismael E. (1977): L'estructura del Parlament de Catalunya i les seves funcions polítiques (1932-1939), Barcelona: Curial Edicions Catalanes.

Sánchez Cervelló, Josep \& Margalef Faneca, M. Cinta (2003): Els límits a la llibertat de premsa a les Terres de l'Ebre durant la Restauració (1875-1923). N 6, Tortosa, Ed. Cooperativa Gràfica Dertosense «El Pont de Barques».

SÁnchez CERvelló, Josep (2012): «El republicanisme a les Terres de l’Ebre en temps del CNR», Recerca. N ${ }^{\mathrm{o}}$ 14, Tortosa: Ed. Arxiu Històric Comarcal de les Terres de l'Ebre, pp. 345-398.

VALls CLUA, Jordi (2013): «Història de la premsa de les Terres de l'Ebre (1880-1901)», Recerca. N $^{\mathrm{O}}$ 15. Tortosa, Ed. Arxiu Històric Comarcal de les Terres de l'Ebre, pp. 159-188.

VALlÈs, Edmond (1977): Història gràfica de la Catalunya autònoma, 1931-1939, Barcelona: Edicions 62.

Recibido el 7 de febrero de 2017 Aceptado el 27 de marzo de 2018 BIBLID [1132-8231 (2018): 95-112] 